Stahle, D.W., et al. Science, 280, 564-567, 1998.

Stahle, D.W., et al. EOS, Transactions of the American Geophysical Union, in press.

Woodhouse, C. \& J.T. Overpeck. Bull. Amer. Meteoro. Soc., 79, 2693 $2714,1998$.

\section{Conceptual Framework for Changes of Rainfall and Extremes of the Hydrological Cycle with Climate Change}

\section{Kevin E. Trenberth}

National Center for Atmospheric Research ${ }^{1}$, Boulder, USA

trenbert@ucar.edu

${ }^{1}$ The $\mathrm{N}$ ational $\mathrm{C}$ enter for Atmospheric Research is sponsored by the $\mathrm{N}$ ational Science Foundation.

A physically based conceptual framework is put forward that explains why an increase in heavy precipitation events should be a primary manifestation of the climate change that accompanies increases in greenhouse gases in the atmosphere. The same arguments apply generally for all kinds of climate change. This paper summarizes Trenberth (1998, 1999) and a full set of references is given in those works.

The term "global warming" is often taken to refer to global increases in temperature accompanying the increases in greenhouse gases in the atmosphere. In fact it should refer to the additional global heating (sometimes referred to as radiative forcing, e.g., by the IPCC (1996)) arising from the increased concentrations of greenhouse gases, such as carbon dioxide, in the atmosphere. Increases in greenhouse gases in the atmosphere produce global warming through an increase in downwelling infrared radiation, and thus not only increase surface temperatures but also enhance the hydrological cycle, as much of the heating at the surface goes into evaporating surface moisture. This occurs in all climate models regardless of feedbacks, although the magnitude varies substantially.

Temperature increases signify that the water-holding capacity of the atmosphere increases and, together with enhanced evaporation, the actual atmospheric moisture should increase, as is observed to be happening in many places. Of course, enhanced evaporation depends upon the availability of sufficient surface moisture and over land, this depends on the existing climate. However, it follows that naturallyoccurring droughts are likely to be exacerbated by enhanced potential evapotranspiration. Further, globally there must be an increase in precipitation to balance the enhanced evaporation but the processes by which precipitation is altered locally are not well understood.

Precipitating systems of all kinds feed mostly on the moisture already in the atmosphere at the time the system develops, and precipitation occurs through convergence of available moisture on the scale of the system. Hence, the atmospheric moisture content directly affects rainfall and snowfall rates, but not so clearly the precipitation frequency and thus total precipitation, at least locally. Thus, it is argued that global warming leads to increased moisture content of the atmosphere which in turn favours stronger rainfall events, as is observed to be happening in many parts of the world, thus increasing risk of flooding. It is further argued that one reason why increases in rainfall should be spotty is because of mismatches in the rates of rainfall versus evaporation.

The arguments on how climate change can influence moisture content of the atmosphere, and its sources and sinks are assembled in the schematic in Fig.1. The sequence given is simplified by omitting some of the feedbacks that can interfere. For example, an increase in atmospheric moisture may lead to increased relative humidity and increased clouds, which could cut down on solar radiation (enhance short-wave cloud forcing) and reduce the energy available at the surface for evaporation. Those feedbacks are included in the climate models and alter the magnitude of the surface heat available for evaporation in different models but not its sign. Figure 1 provides the rationale for why rainfall rates and frequencies as well as accumulations are important in understanding what is going on with precipitation locally. The accumulations depend greatly on the frequency, size and duration of individual storms, as well as the rate and these depend on static stability and other factors as well. In particular, the need to vertically transport heat absorbed at the surface is a factor in convection and baroclinic instability both of which act to stabilize the atmosphere. Increased greenhouse gases also stabilize the atmosphere. Those are additional considerations in interpreting model responses to increased greenhouse gas simulations.

However, because of constraints in the surface energy budget, there are also implications for the frequency and / or efficiency of precipitation. The global increase in evaporation is determined by the increase in surface heating and this controls the global increase in precipitation. But precipitation rates are apt to increase more rapidly, implying that the frequency of precipitation must decrease, raising the possibility of fewer but more intense events.

It has been argued that increased moisture content of the atmosphere favours stronger rainfall and snowfall events, thus increasing risk of flooding. Although there is a pattern of heavier rainfalls observed in many parts of the world where the analysis has been done, flooding records are confounded by changes in land use, construction of culverts, dams and so forth designed to control flooding, and increasing settlement of flood plains which changes vulnerability to flooding.

The above arguments suggest that there is not such a clear expectation on how local total precipitation amounts should change, except as an overall global average. With higher average temperatures in winter expected, more precipitation is likely to fall in the form of rain rather than snow, which will increase both soil moisture and run off, as noted by the IPCC (1996) and found in many models. In addition, faster snow melt in spring is likely to aggravate springtime flooding. In other places, dipole-like structures of precipitation change should occur in places where storm tracks shift meridionally. Beyond this, it is suggested that examining moisture content, rainfall rates and frequency of precipitation and how they change with climate change may be more important and fruitful than just examining precipitation amounts in understanding what is happening in model projections. To be compatible with life times of significant rain 


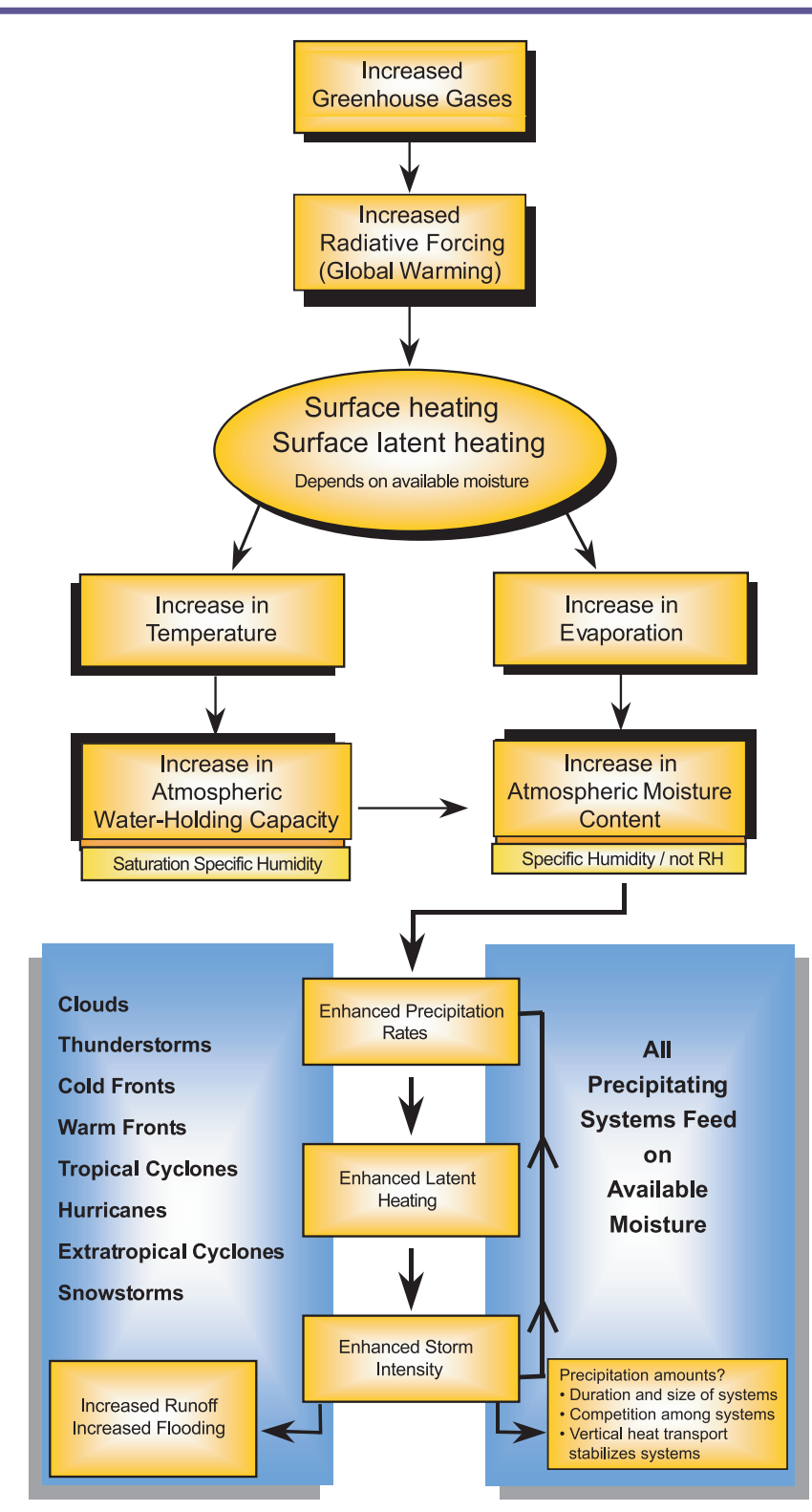

Figure 1: Schematic outline of the sequence of processes involved in climate change and how they alter moisture content of the atmosphere, evaporation, and precipitation rates. All precipitating systems feed on the available moisture leading to increases in precipitation rates and feedbacks. (Trenberth, 1998)

events, yet still deal with whole storms rather than individual rain cells, hourly precipitation data are recommended. Such data are also retrievable from climate models.

\section{References}

IPCC: Climate Change 1995. Eds. J. T. Houghton, et al., Cambridge Univ. Press, Cambridge, U.K., 572pp, 1996.

Trenberth, K. E. Climatic Change, 39, 667-694, 1998.

Trenberth, K. E. Climatic Change, 42, 327-339, 1999.

\section{Century to Decadal Scale Records of Norwegian Sea Surface Temperature Variations of the past 2 Millennia}

\section{Eystein Jansen}

Dept. of Geology, Univ. of Bergen, Bergen, Norway

eystein.jansen@geol.uib.no

\author{
Nalan Koç \\ Norwegian Polar Institute, Tromsø, N orway \\ nalan.koc@npolar.no
}

Recent focus on rapid climate change and millennial scale climate variability in paleoceanography has led to a marked improvement in the temporal resolution of paleoceanographic climate records. Recent studies have indicated a possible existence of pervasive cycles of oceanic variability at approximately 1500 years, both in surface waters and in the strength of North Atlantic deep water flows (Bond et al., 1997; Bianchi and McCave, 1999). These cycles appear to continue into the Holocene (postglacial phase i.e. the last 11,000 years). The last such event may have been the warm-cold alteration normally associated with the Medieval Warm Period (MWP) centred at approximately 1000 AD, and the Little Ice Age (LIA) between 1400 and 1800 AD in Europe. This increased potential for detailed paleoclimatic records from rapidly accumulating sediments, as documented by these and other results, has spurred much interest in the community. The focus has been on obtaining ultra high temporal resolution from sediment cores retrieved from areas where sediment focusing expands the sections and enables detailed sampling. It is also a prerequisite that it is possible to utilise the normal methods of paleoclimatic estimation. This would require open ocean settings and a temporal resolution approaching decadal scale in the best cases. In some very restricted areas annually laminated sediments may be found, which may provide annually resolved paleoclimate records. Outside of these areas, one would need to obtain cores from rapidly deposited sediments in areas of high sediment focusing. Annual resolution is not feasible here.

Using this approach, a pilot study was conducted in high accumulation rate sediments from the Vøring Plateau in the Eastern Norwegian Sea at $67^{\circ} \mathrm{N}$ (IMAGES core MD952011). The study documents SST-variations during the last millennia at hitherto unprecedented resolution (Fig. 1b) from this kind of research. This indicates that careful selection of cores will enable quantitative estimates of ocean proxies approaching decadal scale (see below). The core is dated by ${ }^{210} \mathrm{~Pb}$ and $\mathrm{AMS}-{ }^{14} \mathrm{C}$ (6 dates for the past 2000 years). We estimate the accuracy of the time scale to be about 50 years, which may be somewhat improved in the future by more detailed AMS ${ }^{14} \mathrm{C}$-chronology. The summer SST is estimated using diatom transfer functions. Parallel work using other SST-estimation techniques are underway.

As can be noticed in the figure, SST during the past 2000 years varied around a mean with amplitude of variations of 1-2 degrees. Compared to the thermal optimum of the Early Holocene (data not shown here) the mean SSTs are a few degrees colder, probably due to the long term influ- 